\title{
Social support in type II diabetes care: a case of too little, too late
}

This article was published in the following Dove Press journal:

Diabetes, Metabolic Syndrome and Obesity:Targets and Therapy

21 November 2012

Number of times this article has been viewed

\section{Amudha Kadirvelu \\ Sivalal Sadasivan \\ Shu Hui $\mathrm{Ng}$}

School of Medicine and Health Sciences, Monash University Sunway

Campus, Selangor, Malaysia
Correspondence: Amudha Kadirvelu School of Medicine and Health Sciences, Monash University Sunway Campus, Jalan Lagoon Selatan, 46I50 Bandar Sunway, Selangor, Malaysia

Tel +60355I463I6

Fax +60355146323

Email amudha.kadirvelu@monash.edu
Abstract: Coping with type II diabetic patients is increasingly posing large financial burdens, sorely felt especially by growing economies. Self-management has been found to be an effective approach towards maintaining good control in diabetics. However, although efforts at implementing self-management have had initial success, there has been a lack of sustainability. This review examines the different components impinging on self-care among type II diabetic patients. These include the critical role of social support, the need for support from health care providers, the value of support from family and friends, the influence of sex and cultural factors in self-care behavior, the benefits of peer support, and the role of literacy in diabetes self-care. Despite the mounting evidence for the effectiveness of social support in diabetes care, and the various stakeholders including this in their clinical guidelines, there has only been a lukewarm response from policy-makers towards ensuring its implementation. Hence, more effort is required from health care providers in moving away from just understanding the effects of new drugs and subsequently putting their patients on these drugs, and going back to the basics of communicating with the patients, understanding their woes, and helping to motivate/empower their patients. This paper analyzes the various components of social support, their influence on diabetes self-care, and how health care providers can help in this process.

Keywords: type II diabetes mellitus, social support, self-management/self-care

\section{Introduction}

Diabetes mellitus (DM), one of the fastest-growing and the most alarming of chronic illnesses, refers to a group of metabolic diseases characterized by abnormally high blood-glucose levels. DM and its associated complications impose a huge health care burden worldwide, presenting major challenges to patients and health care systems besides national economies. This burden is expected to increase further with the International Diabetes Federation's prediction of an increase in the number of individuals with diabetes from 240 million in 2007 to 380 million in 2025, with $80 \%$ of the disease burden in lower- and middle-income countries. ${ }^{1}$ What is more alarming for this region is the expectation that more than $60 \%$ of this population with DM will come from Asia, implying substantial increases in prevalence in each country in the coming decades, especially so in developing countries with the most rapid economic growth. ${ }^{2}$ India and China would thus have the highest number of persons with DM in Asia. It was projected that DM would have claimed 1,008,000 lives in India, 575,000 in China, and 231,000 in the US in $2010 .^{3}$

Many factors have contributed to this global epidemic. Though increasing obesity and decreasing physical activity play a significant role in the steady increase of the 
diabetic population globally, in countries like China and India a multitude of factors are involved. These include limited access to affordable treatment, rural-urban migration, urban slums, increasing affluence with a trend towards unhealthy Westernized diets, breakdown of family support, genomic diversity with migration to more developed countries in the region, and interracial marriages. Improved modes of transport and mechanization of labor-intensive tasks have contributed to the reduced physical activity. Apart from these, another major contributing factor is stress arising from working long hours, intense competition at the workplace, and holding multiple jobs, all resulting in lack of time for exercise and an overall neglect of personal health.

Consequently, changes in health behavior, promotion of a healthy lifestyle, and self-management in concordance with professional treatment advice are the cornerstones of diabetes care, specifically type II DM. However, not surprisingly, these are also the most difficult tasks people with type II DM face. This then results in poor diabetic control: about a third to half of the patients with type II DM show inadequate control of blood-glucose levels and have cardiovascular risk factors regardless of the diabetes care system implemented. ${ }^{4} \mathrm{~A}$ recent Norwegian survey revealed that only $7 \%$ of adults with diabetes attained the optimal metabolic control ideal for preventing complications. ${ }^{5}$ Similar results have been found in other countries. ${ }^{6}$ As a consequence, many suffer from macro- and microvascular diabetic complications like coronary heart disease, stroke, blindness, nephropathy, and peripheral neuropathy, as well as decreased quality of life, decreased functional status, emotional distress, and elevated death risks. ${ }^{7}$ This poses a considerable disease burden and subsequent huge economic implications, particularly to Asian countries with developing economies. It has been estimated that global health expenditure for prevention and treatment of diabetes will rise to more than $\$ 302.5$ billion by 2025 from $\$ 232$ billion in $2007 .^{2}$

Since people with diabetes use a disproportionately greater share of health care resources, exploration of traditional and nontraditional ways to help manage the disease appears to be urgently warranted. Unfortunately, research and formulation of guidelines on patient perspectives, patientprovider interaction, and patient empowerment in diabetes care and education have not received the consideration they deserve,${ }^{8}$ in contrast to the discovery of newer therapeutic agents. The role played by the families of diabetics, as well as other forms of social support in diabetes care, has also not been given sufficient attention. ${ }^{9}$

Currently, there is increased emphasis on curative care at the expense of preventive and promotive care. Unfortunately, while this model seems to have worked reasonably well until recently in developed countries, major constraints are faced in lowincome countries. People in these countries encounter barriers to treatment and prevention as a result of a lack of physical and financial access to health care, as well as a result of poor implementation of potentially effective preventive and promotive policies, due mainly to political influences and the influence of multinational pharmaceutical companies. Apart from this, the lack of care tailored to individuals due to insufficient training or knowledge of health care providers is a major problem. Other factors include the lack of support from policy-makers and frequent changes of government in some of these countries, resulting in a lack of sustained policies.

Some efforts have been made in implementing self-care among diabetic patients, but have lacked sustainability, possibly due to inadequate consideration of the many facets that are involved. In this review, we discuss social support, the components of the social support framework, and the critical role it plays in diabetes self-care. Improved knowledge of the benefits of social support, particularly among health care providers, is vital towards enhancing diabetes patients' self-care, ensuring adherence to professional advice, encouraging lifestyle modifications, and ultimately improving the outcomes of diabetes care.

\section{Self-management}

Self-management of a chronic illness refers to the daily activities that individuals undertake to keep their illness under control and minimize its impact on their physical health and functioning, as well as enabling them to cope with the psychosocial sequelae of their illness. ${ }^{10}$ Despite the advances in therapeutics for diabetes management, the self-management activities of diabetes remain complex, with difficulties being encountered in incorporating treatment recommendations into the current lifestyles of diabetics. ${ }^{11}$ It is not surprising then that care is to be centered on the patient rather than on their "disease," which was advocated (for diabetes) more than a decade ago. The empowerment approach to diabetes care recognizes that the patient is the source of control, having the responsibility for decision-making and action in his/her day-to-day management of the condition. This would necessitate a change in the management approach from a physician-centered model to a proactive patient-centered model, as shown in Figure 1. This implies that patients need to adopt behaviors that help them engage in the process of actively self-managing their diabetes.

Self-management as informed by social cognitive theory ${ }^{12}$ emphasizes that both personal (especially beliefs and other 


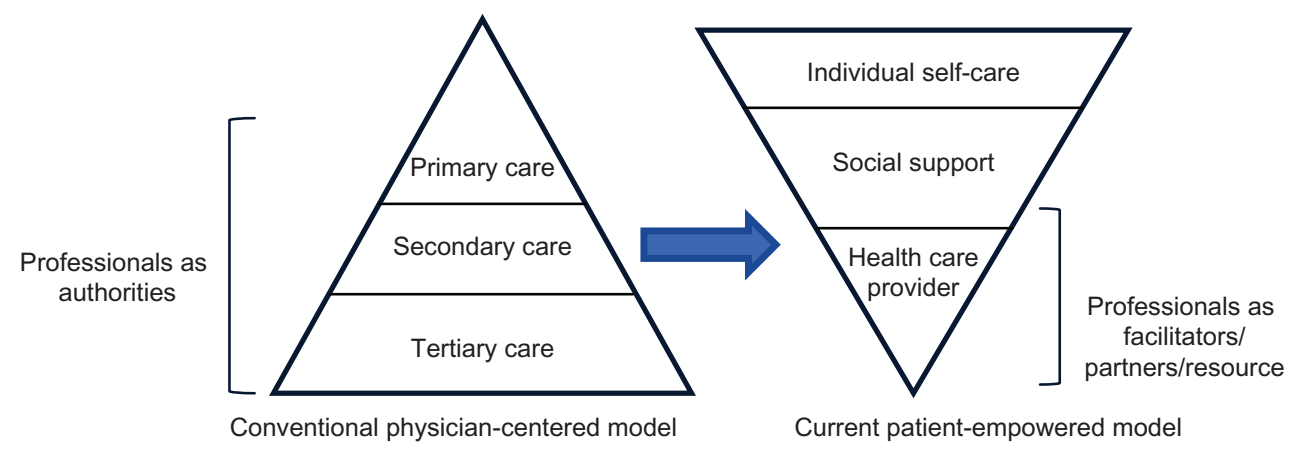

Figure I Shift in the model of management of diabetes.

Adapted from Ferguson T. Consumer health informatics. Healthc Forum J. 1995;38:28-33.

cognitions) and environmental factors (both physical and social) interact in influencing behavior. For the most part, self-efficacy - an individual's confidence in his/her ability to undertake specific self-management behaviors - has been highlighted as the main influence on successful selfmanagement. ${ }^{10}$ However, as social cognitive theory illustrates, chronic illness self-management does not occur in a vacuum but rather in a context that includes formal health care providers, informal social network members (friends and family, peers), and the physical environment (eg, housing, air quality). All of these contextual factors have the potential to significantly influence self-management behavior, either directly or indirectly through self-efficacy.

Compared to other chronic illnesses, type II DM entails significant self-management components that include specific activities and behaviors, such as measuring blood-glucose levels, taking multiple medications at appropriate times, recognizing and responding to symptoms, managing acute episodes, maintaining an optimal diet, physical activity, weight management, smoking cessation, managing psychological responses to illness, and managing relations with significant others. ${ }^{10}$ Although these activities are typically undertaken in cooperation with a health care provider, self-management is more than just strict adherence to a prescribed behavioral regimen. It involves a high level of control on the part of the patient, some autonomy with respect to adjusting the regimen as necessary, and deliberate decision-making and problem-solving.

For effective self-management, motivation is critical. ${ }^{13}$ An individual's motivation to self-manage their disease may be influenced by many factors - demographic, psychological, disease- and treatment-related - in which the role of social support is one of the most important.

\section{The role of social support}

Social support can be defined as "an exchange of resources between (at least) two persons, aimed at increasing the well-being of the receiver."14 Social support is receiving increased attention as a mediator or moderator of health outcomes. ${ }^{15}$ While the exact mechanism at work remains unclear, it has been hypothesized that social support may work either directly, resulting in beneficial effects for a person regardless of the existing stress level, or indirectly, by providing a resource to modify the detrimental influence of high-level stress conditions. ${ }^{16}$ Apart from familial relatives, peers, friends, neighbors, colleagues, fellow patients, or even penfriends, social networking on the Internet may play a role in social support.

For many diabetics, the day-to-day management of their condition can be overwhelming. ${ }^{17}$ A number of factors including family, social network, and, importantly, cultural beliefs could influence perception, coping, and subsequent self-care behavior. ${ }^{18}$ Studies have shown that subjects diagnosed with diabetes experience psychosocial challenges that can have significant effects on their lives. ${ }^{19}$ In fact, many diabetics struggle with the loss of freedom in decision-making, particularly in food choices, as well as often perceiving deterioration in their quality of life. It is of no surprise then that emotional factors play a major role in the management of diabetes. People with diabetes have often been found to experience high levels of diabetes-related emotional distress as they manage their fluctuating blood-glucose levels, leading to poor self-management as a result of experiencing "diabetes burnout." 17 This in turn can lead to conditions like depression, which is reported as being twice as common in subjects with diabetes compared to the rest of the population. ${ }^{20}$ This can have far-reaching consequences on diabetic patients. A recent systematic review found that these depressive symptoms markedly impair their health-related quality of life. ${ }^{21}$ In addition, depression and related factors can interfere with self-care activities and affect glycemic control, leading further to increased risks of morbidity and greater health care costs. ${ }^{17}$ 
Social support plays an important role in the management of diabetes. The positive association of social support with (better) glucose-level control in type II diabetes has been explained in different ways. Some suggest that the social network provides a substantial part of the information that a patient receives on the diagnosis, treatment, complications, and expectations of diabetes. ${ }^{7}$ The social network can offer emotional support in the form of cognitive support, involving the provision of information, knowledge, and advice, offer of material support, or also the offer of goods and materials. ${ }^{22}$ Besides the appraising and informative effects, such emotional support would foster feelings of comfort and alter the perceived stress and physical reactions that the patient endures. Social support may also offer coping strategies and structure in daily routines, enabling the patient to cope with stressful events, follow the treatment regimen in times of stress, and reduce the likelihood of stress leading to poor health. ${ }^{23}$ Figure 2 illustrates the components of the social support network and the dimensions of support provided by such a network.

Since treatment guidelines for diabetes often necessitate making changes in everyday lifestyle patterns of these patients, the social world of a person living with diabetes becomes an important factor in this process. Some of the characteristics inherent in existing social connections have the potential to adversely affect the ability of people with diabetes to provide for their self-care. A better understanding of how these social networks contribute to health-related outcomes has been gained through the examination of social support systems. Previous studies have reported that the lack of social relationships is a major risk factor for morbidity and mortality, especially among men. ${ }^{24}$ On the other hand, positive social support has been associated with improved medication, dietary ${ }^{25}$ and exercise adherence, ${ }^{26}$ decreased depression, ${ }^{27}$ smoking cessation, ${ }^{28}$ good diabetes self-management, and improved clinical outcomes. ${ }^{29}$ Many similarly encouraging reports have caused greater attention to be paid to the concept of social support, resulting in it becoming a core component of diabetes care in recent years.

Thus, it can be seen that social support and social network play a major role in self-management among diabetic patients. In many instances, social support is a positive resource, although it also has the potential for negative effects. ${ }^{26}$ Interactions that foster dependence ${ }^{30}$ or that are perceived to be criticism ${ }^{31}$ may inhibit attempts to engage in self-care behavior.

\section{Health care provider support}

As diabetes is a lifelong disease involving regular consultation with health care providers, it would be logical to conclude that firm support from these practitioners is critical for effective diabetes management. Stewart ${ }^{32}$ elaborates that the social support offered by health care practitioners includes emotional, affirmational, informational, and tangible attributes. Several authors have demonstrated that support from health care practitioners is integral to people learning how to selfmanage diabetes. ${ }^{33-35}$ For instance, it was found in a survey that more than $40 \%$ of participants identified their physician as having provided the greatest social support in managing their diabetes. ${ }^{35} \mathrm{~A}$ central theme for social support is empowerment,

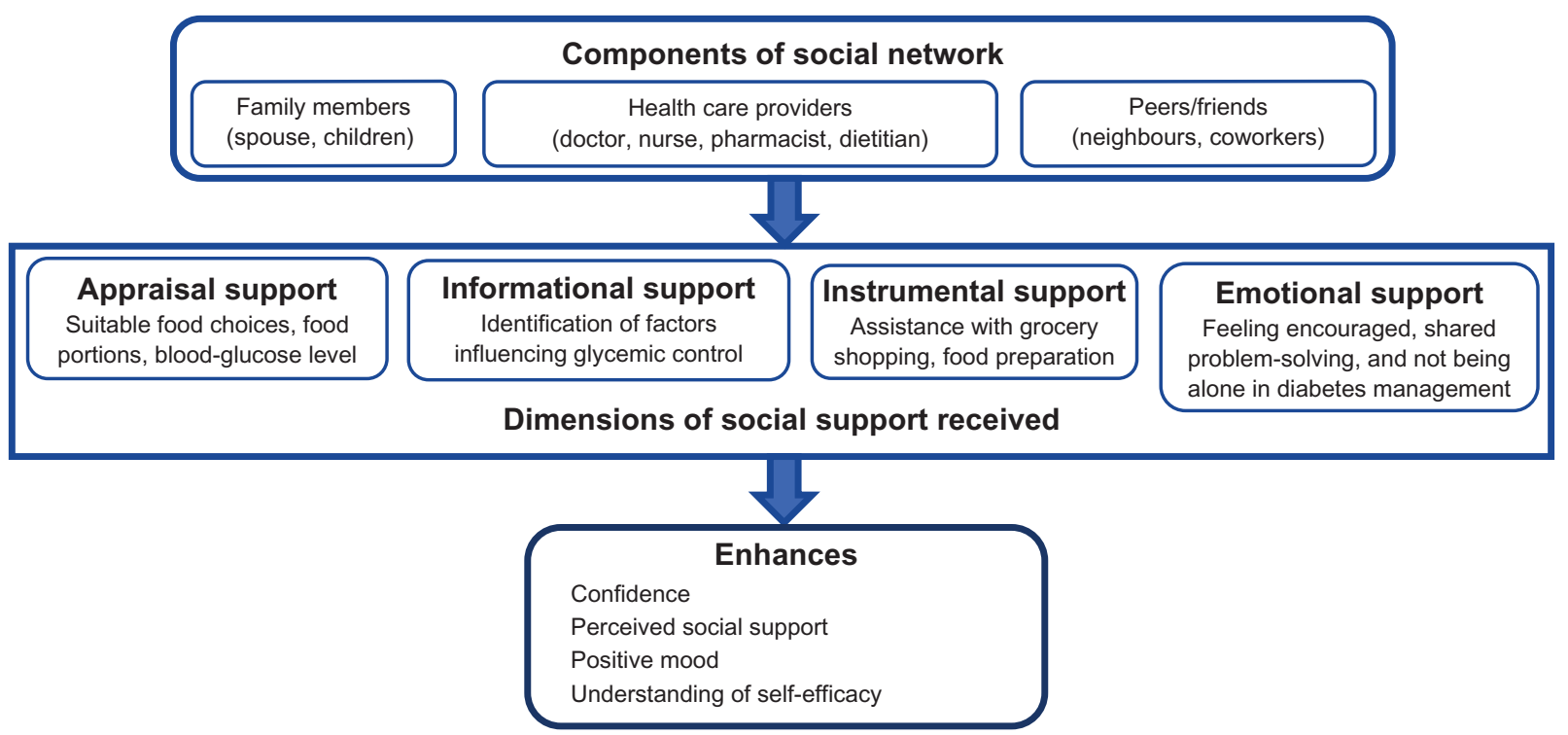

Figure 2 Components of social support network and its benefits. 
which refers to providing people with chronic disease and their caregivers with the maximum amount of control over their own lives. It has been reported that this can enhance subjective quality of life for persons with chronic disease. ${ }^{36}$

Health care practitioners can promote self-management in their diabetic patients by carrying out patient-centered activities. For patients who rely primarily on their physician for support, effective patient-physician communication may be particularly important, with evidence to show that patients practiced better self-management when their providers had superior communication skills. ${ }^{37}$ Health care professionals need to pay attention to various aspects like style and content of verbal interaction, verifying patient understanding, determining perceptions of key messages, and other strategies in fostering behavior change. ${ }^{38}$ To ensure that patients recognize the importance of self-management and become fully engaged in it, there should be negotiation of goals to help health care providers and patients achieve a balance between accepting medical care and desiring to live a normal life.

It has been suggested that every patient should have a specifically designed individualized strategy, since each may present with a unique set of needs, risks, and limitations. ${ }^{39}$ Such a personalized strategy is based on the premise that different patients with chronic disease may respond to similar treatments in different ways. If all patients were to be treated using a broad-brush approach, this would be at the expense of disregarding their individual sociocultural differences and characteristics. This has enormous potential to add value to the management of patients with chronic disease by providing targeted treatments, improving quality of life, and being more cost-effective.

The provision of practical support from health care practitioners is essential to meet patients' expectations of being able to practice specific diabetes-control behavior. Having empathy and an ability to build trust are useful attributes that may help health care professionals bring about behavior change, so that they can provide individualized, practical, and ongoing support. ${ }^{17,39}$ Despite the fact that this area seems to be rarely addressed in type II diabetes research, there are some studies that have highlighted its importance in promoting self-management. A recent study reported that diabetic patients receive unsatisfactory levels of practical information from their doctors. ${ }^{39}$ Thorne et $\mathrm{al}^{40}$ postulated that information is not provided due to the fact that health care practitioners consider it to be an individual family matter rather than a basic concern of the health care system.

Diabetics require continuous support from health care providers, especially in self-management, since maintaining the prescribed lifestyle behavior could pose a major challenge for them. Despite the current trend of a technology-based approach based on new drug-delivery systems and new drugs, patient outcomes with respect to diabetic control have been poor. The evidence suggests that there is a need to fall back on the age-old doctor-patient communication, with special emphasis on personal contact and rapport. This seems to matter more, especially to patients with chronic disease: more attention may have to be devoted to strategies like home visits, doctors from community clinics playing a greater role in chronic disease management, greater emphasis on home visits by nurses dedicated to chronic disease, and further involvement of family members.

\section{Support from family and friends}

Besides support from health care providers, the patients' families and friends can provide support to assist in overcoming social barriers and executing complex self-management behavior, especially since self-management tasks such as glucose testing, insulin injection, diabetes meal planning, checking feet, and exercise often take place in social settings, and can alter family and social routines. Moreover, behavioral modifications pose challenges when made alone by the patient. Practical and emotional assistance from family and friends may have a positive influence on global measures of diabetes self-management behavior. Various studies both among predominantly white populations as well as AfricanAmerican and Latino adults with diabetes found a positive correlation between family-and-friend support and diet, exercise, foot care, testing for sugar, and compliance with medication. ${ }^{41}$ There is also evidence that the inclusion of a family member in psychosocial interventions for chronic illnesses like diabetes may improve outcomes. ${ }^{42}$ However, the role of family factors in adult diabetes-intervention research has been neglected, particularly in type II diabetes. ${ }^{43}$

While social support is for the most part a positive resource, clinicians need to be aware of potential negative effects that may inhibit self-care behavior and undermine self-management goals. ${ }^{44}$ In most instances, support from family and friends is freely given, but there is a tendency for this to be provided principally during acute stages of a disease, ie, when the disease is initially diagnosed, there is poor progression of diabetes, or when the person is terminally ill, but tends to reduce when the disease continues over an extended period of time. Qualitative studies also indicate that patients can sometimes feel criticized, nagged, or guilty about receiving help from family members, ${ }^{45}$ or family support could be poorly executed where they do not undertake 
illness-care tasks on the patient's behalf, leading to worse patient outcomes. ${ }^{46,47}$ These family barriers to self-care could particularly affect younger, more functionally able patients, who are often trying to juggle multiple active family roles themselves (eg, parent, child, and spouse). ${ }^{48}$ Other barriers could be where patients may be socially isolated or have conflicted family relationships that may undermine diabetes management.

Clinicians should thus be aware of the benefits of support from family and friends, as well as be alert to family barriers to self-care, even in families that seem to have good overall function. This is especially true of younger patients as well as female patients.

\section{Cultural factors}

Cultural practices and family characteristics have also been shown to influence diabetes self-management behavior. ${ }^{49,50}$ The importance of cultural beliefs alongside family and social factors in the formation of a person's explanatory model of health and illness was emphasized back in the 1970s by Kleinman. ${ }^{18}$ For example, in a study by Heisler et al, African-American and Hispanic/Latino participants identified their belief in God as a source of strength and an important resource for diabetes management. ${ }^{37}$ On the other hand, fatalism was another source of variation that was negatively associated with diabetes self-management among African-American adults. They felt that diabetes is not controllable, that the disease is an inevitable generational fate - a death sentence. ${ }^{50} \mathrm{~A}$ study by Heuer and Lausch among Hispanic migrant workers in the United States that elicited their perceptions of living with diabetes showed cultural folk beliefs prevailed in forming health perceptions. ${ }^{51}$ Another study by Chesla et al that examined personal health models reported that Latino Americans' representations were based on a holistic perspective of health, reflecting ethnic/cultural beliefs, whereas the European Americans' models were oriented more towards biomedicine. ${ }^{52}$

The cultural impact on illness representations was also illustrated in a Taiwanese study where people with diabetes indicated that exercise was a suitable management strategy because it eliminated toxins in the sweat. ${ }^{53} \mathrm{~A}$ study comparing the illness perceptions of Caucasians and Asians in England reported that Asians used alternative medication to supplement Western medicine, based on advice by their social support network. ${ }^{54}$ In New Zealand, a comparative study of European New Zealanders and those of Tongan descent found that the latter believed God's will as well as environmental pollution were more likely to have caused their diabetes. ${ }^{55}$
Recent studies in developing countries have found that cultural factors can also influence health-care-seeking behavior. A study of Ugandan diabetics showed that underlying living conditions, such as affordability of drugs, food, equipment for self-monitoring of blood-glucose, and different gender roles, determined health-related behavior, including health-care-seeking behavior. ${ }^{56}$ In another study, newly diagnosed diabetics sought help mainly from nurses and physicians in the professional health care sector, with females going more often to free governmental institutions and males to private-for-profit clinics. Where there is perceived failure of conventional health care to manage diabetes or its related complications, many, particularly women, turn to traditional healers and herbalists for traditional herbs or food supplements. ${ }^{57}$ On the other hand, an independent association with complementary and alternative medicine use was shown in Malaysians with a higher educational level and higher income. ${ }^{58}$ A study of an Indian community in South Africa showed that complementary and alternative medicine was mainly used for chronic conditions such as diabetes if conventional health care failed to cure the underlying condition. ${ }^{59}$

Despite these variations in beliefs and practices, the social support offered by family and friends of different cultures has been shown to have positive influences on diabetes self-management. The major impact of cultural variations and beliefs needs further acknowledgment and acceptance. This is of particular concern in Asian countries that are home to many different cultures and races. For example, the issue of male dominance resulting in the neglect, reduced attention, or even lack of resources for the management of females with chronic disease can be highlighted. Other issues include differing health care systems and the consequent differing degrees of access to health care providers, the gap between the rich and poor in developing countries, and differing literacy levels both within countries as well as across countries in the region.

\section{Sex and self-care behavior}

Sex along with age and marital status may have overlapping influences on self-management. Connell et al found that social support had only a positive association with general morale among women, while there was a direct correlation between social support and adherence to treatment among older men with diabetes. ${ }^{60}$ Among older adults, it has been found that women tend to exhibit better self-care behavior, are less likely to be married, and are more likely to discuss personal issues with friends than men are. ${ }^{61}$ On the other 
hand, men are more likely to have a family member who assists with various aspects of their self-care regimen. ${ }^{62}$ The self-care behavior of older women with type II diabetes is also influenced by social role obligations, and this is especially true of certain communities like the African-American community, where women often bear a greater responsibility as the caregiver for the entire family. ${ }^{45}$ Predictably, such women also report a lower quality of life as well as encountering more impediments to the self-management of their diabetes.

\section{Peer support}

Peer support refers to programs that use nonprofessionals who have diabetes or those with close familiarity with its management to assist patients in managing their own health. Peer support assists in daily management, provides social and emotional support, and acts as a link to clinical care. Since the control of chronic diseases arguably presents a greater challenge than just merely promoting adherence to a scheduled test or service, there is growing interest in peer support for persons with diabetes and other chronic diseases. Initiatives such as the United Kingdom's Expert Patient Programme ${ }^{63}$ have shown it to be a promising approach to increasing the quality and quantity of support. There is a wide range of research showing that people living with diabetes have much to offer each other. Peer-to-peer interventions are being widely used in New Zealand, are in demand by patients, and appear to be of quantitative benefit in primary prevention. ${ }^{64}$ A recent randomized trial by Heisler and colleagues ${ }^{65}$ on the role of peers in improving diabetes outcomes in patients with high glycated hemoglobin $\left(\mathrm{HbA}_{1 \mathrm{c}}\right)$ levels found a significant improvement after 6 months in patients in the intervention group, who also initiated insulin therapy more often than those in the control group. This suggests that peer support provides sustained nonjudgmental assistance as desired by the diabetic patients.

A recent study demonstrated that patient-level factors accounted for the majority of variation in $\mathrm{HbA}_{1 \mathrm{c}}(98 \%)$ compared to physician-related factors, in relation to metabolic control in type II diabetes. ${ }^{66}$ Peer support can thus offer emotional, social, and practical assistance to patients to achieve and sustain complex behaviors that are critical in managing their condition and staying healthy. It can complement and enhance other health care services to help people follow management plans in daily life, stay motivated, and cope with the stressors of chronic disease, and at the same time stay connected to their health care providers to get the care they need, often in a cost-effective manner. ${ }^{39}$ Peer support can be a constant link for people living with a chronic disease or condition, so that there is sharing of knowledge and experience that others (including many health workers) do not have, as well as providing practical and emotional support for behavior change. ${ }^{67}$ Moreover, many patients with poor glycemic control requiring either initiation or intensification of insulin therapy have been found to resist these because of concerns about the additional self-management burdens. ${ }^{68}$ Peer support may especially benefit those dealing with challenging medical tasks such as insulin management.

There is currently limited evidence on the effectiveness of peer support in the management of diabetes, particularly in developing countries. Initial results from a recent study that assessed peer support for self-management in Cameroon, South Africa, Thailand, and Uganda found improvements in symptom management, diet, blood pressure, body mass index, and blood sugar levels. ${ }^{69}$ Key functions of effective peer support in the study included assistance in daily management, social and emotional support, linkage to clinical care, and ongoing availability of support. Encouraging results from this study suggest that diabetes-management programs using peer support can be successfully introduced across varied cultural settings and within diverse health systems.

While peer support is extremely effective, health care practitioners need also to be aware of the potential barriers to peer support. These include a lack of proper training of peer workers/volunteers and lack of support, feedback, and recognition of the efforts of peers, especially from institutional staff, and a lack of supervision, monitoring, and evaluation of peers by the institution. This may happen especially if peer support is not accepted or acknowledged by the health system. It is paramount that peer support programs are tailored to fit the target patient groups for effective integration into general practice, taking into account various factors including sociocultural practices and education levels of the target groups.

\section{Health literacy and diabetes self-care}

Health literacy is defined as "the degree to which individuals have the capacity to obtain, process, and understand basic health information and services needed to make appropriate health decisions." ${ }^{, 70}$ Health literacy is known to play a significant role in self-care, ${ }^{71}$ adherence to medication, ${ }^{72}$ and clinical outcomes. ${ }^{73}$ Health care providers are often unaware that up to half of the patients they see may have inadequate literacy. ${ }^{74}$ Limited health literacy is common among individuals with diabetes ${ }^{75}$ and has been associated with poor diabetes knowledge, fewer self-care behaviors, ${ }^{73,74}$ 
more self-reported complications, ${ }^{76}$ increased health care costs, ${ }^{77}$ poorer understanding of physicians' instructions, ${ }^{78}$ and worse glycemic control. ${ }^{73}$ This implies that nurses and other providers need to make a conscious effort to simplify care, tailor education, and reduce the complexity of the health care system.

The mechanisms linking health literacy to diabetes selfcare and clinical outcomes are poorly understood. Bains and Egede $^{79}$ reported that knowledge on diabetes and perceived health status are the most important factors associated with glycemic control. Osborn et a ${ }^{80}$ suggest that health literacy has an indirect effect on diabetes self-care and glycemic control through social support.

Increasing the patients' knowledge of therapeutic options, personal health status, value of treatment, and preferences, as well as enhancing skills necessary to carry out required health activities by improving health literacy and self-efficacy (an individual's belief that they can change their behavior to attain the required therapeutic goals), can empower, motivate, and engage individuals, whatever their health-literacy status, to improve their health outcomes.$^{81}$ However, health care professionals need continually to verify that individual patients understand why it is important to follow the recommended advice, and what it is they need to do ${ }^{82}$ Health care professionals often assume that behavioral change is a natural consequence of consultations with individuals with high health literacy, believing that once an individual has been provided with information and advice, they will always act on it and adopt the required changes immediately. However, it is estimated that patients recall very little (less than 50\%) of what they are told during their consultations. ${ }^{83}$

Paasche-Orlow and Wolf ${ }^{84}$ suggested that clinicians need to assess how well their individual patients understand health information. Recent studies have suggested that clinicians could use a few questions to identify patients with limited health literacy ${ }^{85}$ Self-rated reading ability, highest education level attained, and the single-item literacy screener can each provide clinicians with valuable information about a patient's learning needs. ${ }^{86}$ Based on the level of literacy, patients' health care teams should provide simplified education and ensure that patients understand and retain what is being said. ${ }^{87}$ Aggressive educational interventions have shown some additional benefit in outcomes among patients with limited health literacy. ${ }^{88}$

There needs to be a conscious effort to adopt interventions based on a deeper understanding of the needs and competencies of patients with poor health literacy. Development of strategies to communicate more effectively with patients who have poor health literacy are needed at the patient-clinician level and the patient-social support network level. ${ }^{89}$ Effective office-based communication skills should be instilled early in the medical program of trainee doctors suitable for patients across cultures and with poor literacy.

\section{Implications for practice}

Self-management plays a crucial major role in the management of diabetes and can have a major impact on the extent of diabetic control. Social support and the social network have an important bearing on self-management among diabetic patients.

A key strategy that should be adopted in management of type II diabetes is the use of the personalized approach, where the focus is on tailoring treatments as closely as possible to patients' needs. Such personalized health care has tremendous potential to add value to the management of these patients, providing benefits such as increased quality of life, and being cost-effective by helping to avoid disadvantageous and/or unnecessary treatment. The treating physician should take into account the social support network of a diabetic and the levels of influence (Figure 3) that the network has on self-care behavior when designing the treatment/health care goal for the individual. Such personalized therapy should take into account the individual's

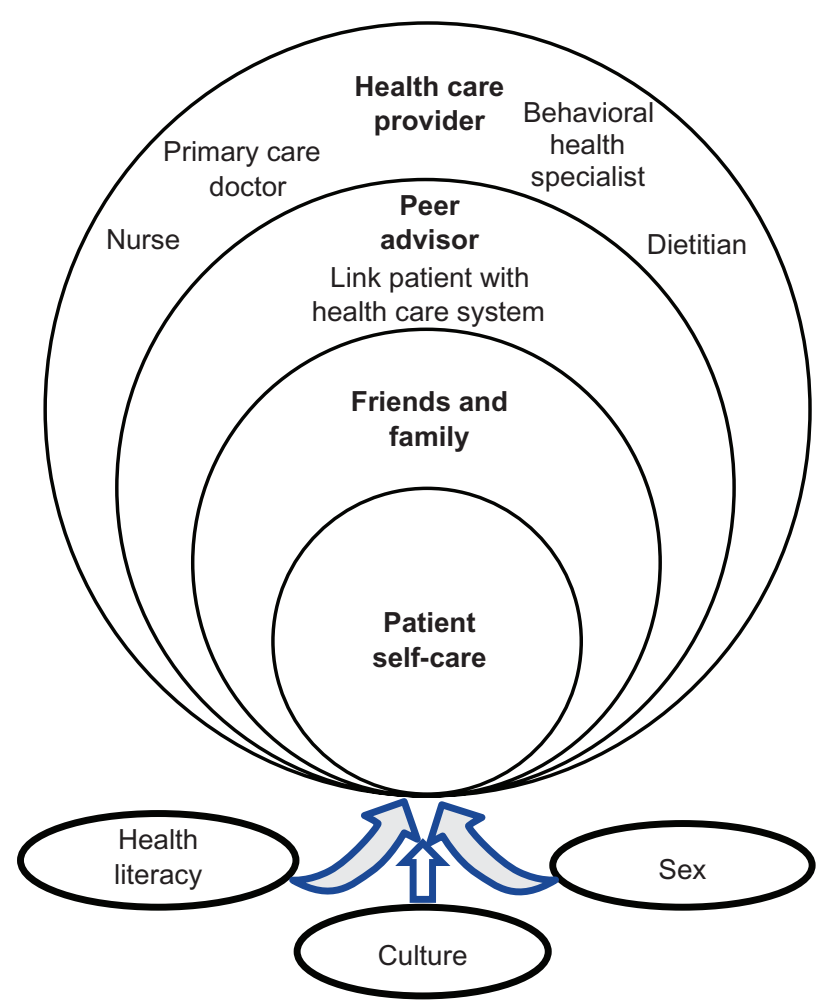

Figure 3 Levels of influence of social support networks in diabetes self-care. 
health literacy, demographic factors, and cultural values and beliefs on disease management.

It is important that health care practitioners are aware of the barriers to social support that may be needed to be overcome. This may stem from problems related to patients, or arising from family relationships, or sometimes from family members themselves. Barriers may also exist in peers in general, related to areas like training, institutional support, and recognition.

It may not always be possible for the lone treating physician to be cognizant of all the issues that could impair effective diabetes self-management. All members of the health care team, including nurses, pharmacists, dietitians, and behavioral specialists such as psychologists, should ideally work together for the comprehensive assessment of each diabetic patient on an individual basis and initiate the most appropriate therapy to achieve the optimal health care goal. To effect positive health-behavior change, health care providers should always adopt a patient-centered approach and cultivate a collaborative relationship with the diabetic patient.

A system of collaborative care needs to be instituted where patients have a degree of autonomy motivation to be able to carry out optimal self-care. This implies comanagement care where a care plan that includes goals is developed through negotiation and agreement among patients, health care providers, family, carers, and other supports. Health care providers also provide ongoing support to work towards optimal patient self-care behaviors in time. The prerequisites of this empowerment approach are cooperation and respect, where patients are recognized as being fully responsible for self-management of their diabetes and in control of decisionmaking, with an adult-to-adult relationship between health care practitioners and patients.

Chronic-disease management will benefit greatly from national policies that emphasize the importance of social support in chronic-disease management. There is also a need to increase public awareness of the major role of social support. The health care provided to patients with chronic disease can be greatly enhanced by incorporating social support strategies as well as by the sharing and exchange of information on successful social support strategies that have contributed to significant improvement in health status and outcomes among patients with chronic disease.

\section{Conclusion}

While there have been unparalleled advances in technology, health care systems are beginning to admit that medical interventions alone are far from sufficient to totally control chronic diseases like type II diabetes, let alone manage them effectively. With the rapid rise in the elderly population combined with ever-increasing life spans and the advent of a technology-dependent medical model of disease management, severe strains are being imposed on health systems in both developed and developing countries. Consequently, many health systems are exploring different models of care and advocating approaches that place more emphasis on a patient-centered approach. It is evident that social support has much unrealized potential as both an effective and costeffective modality in the war against the epidemic of type II diabetes. While health practitioners need to be aware of the barriers to social support, it is clear that the way forward is a collaborative model involving health care providers, patients, and their social support network.

\section{Disclosure}

The authors report no conflicts of interest in this work.

\section{References}

1. International Diabetes Federation. IDF Diabetes Atlas. 5th ed. Brussels: IDF; 2011.

2. International Diabetes Federation. IDF Diabetes Atlas. 3rd ed. Brussels: IDF; 2006.

3. Roglic G, Unwin N. Mortality attributable to diabetes: estimates for the year 2010. Diabetes Res Clin Pract. 2010;87:15-19.

4. Hirsch IB. The burden of diabetes (care). Diabetes Care. 2003;26: 1613-1614.

5. Claudi T, Ingskog W, Cooper JG, Jenum AK, Hausken MF. Quality of diabetes care in Norwegian general practice. Tidsskr Nor Laegeforen. 2008;128:2570-2574. Norwegian.

6. Saydah SH, Fradkin J, Cowie CC. Poor control of risk factors for vascular disease among adults with previously diagnosed diabetes. JAMA. 2004;21:335-342.

7. Winocour PH. Effective diabetes care: a need for realistic targets. BMJ. 2002;324:1577-1580

8. Dam Van H, Van Der HF, Van Den BB, Ryckman R, Crebolder H. Provider-patient interaction in diabetes care: effects on self-care and outcomes. A systematic review. Patient Educ Couns. 2003;51:17-28.

9. Griffith LS, Field BJ, Lustman PJ. Life stress and social support in diabetes: associations with glycemic control. Intl J Psych Med. 1990;20: 365-372.

10. Clark NM, Becker MH, Janz NK, Lorig K, Rakowski W, Anderson L. Self-management of chronic disease by older adults. J Aging Health. 1991;3:3-27.

11. Odegard PS, Capoccia K. Medication taking and diabetes: a systematic review of the literature. Diabetes Educ. 2007;33:1014-1029.

12. Tobin DL, Reynolds RVC, Holroyd KA, Creer TL. Self-management and social learning theory. In: Holroyd KA, Creer TL, editors Self-Management of Chronic Disease. New York, NY: Academic Press; 1986:29-55

13. Peyrot M, Rubin RR. Behavioral and psychosocial interventions in diabetes: a conceptual review. Diabetes Care. 2007;30:2433-2440.

14. Shumaker SA, Brownell A. Towards a theory of social support: closing conceptual gaps. J Soc Issues. 1984;40:11-36.

15. Berkman LF. Measures of social networks and social support: evidence and measurement. In: Ostfeld AN, Eaker ED, editors. Measuring Psychosocial Variables in Epidemiologic Studies of Cardiovascular Disease. Washington, DC: NIH Publication/Public Health Service; 1985:51-79. 
16. Cohen S, Syme SL. Social Support and Health. Orlando, FL: Academic Press; 1985.

17. Clark M. Diabetes self-management education: a review of published studies. Prim Care Diabetes. 2008;3:113-120.

18. Kleinman A. Patients and Healers in the Context of Culture: An Exploration of the Borderline Between Anthropology, Medicine and Psychiatry. Los Angeles, CA: University of California Press; 1980.

19. Peyrot M, Rubin RR. Levels and risks of depression and anxiety symptomatology among diabetic adults. Diabetes Care. 1997;20:585-595.

20. Lustman PJ, Anderson RJ, Freeland KE, De Groot M, Carney R, Clouse RE. Depression and poor glycemic control: a meta-analytic review of the literature. Diabetes Care. 2000;23:934-942.

21. Ali S, Stone M, Skinner TC, Robertson N, Davies M, Khunti K. The association between depression and health-related quality of life in people with type 2 diabetes: a systematic literature review. Diab Metab Res Rev. 2010;26:75-89.

22. Jacobsen DE. Types and timing of social support. J Health Soc Behav. 1986:27:250-264

23. Sarazon BR, Sarason IG, Gurung RAR. Close personal relationships and health outcomes. A key to the role of social support. In: Duck S, editor. Handbook of Personal Relationships. New York, NY: Wiley; 1978:547-573.

24. Uchino BN, Cacioppo JT, Kiecolt-Glaser JK. The relationship between social support and physiological processes: a review with emphasis on underlying mechanisms and implications for health. Psychol Bull. 1996;119:488-531.

25. Garay-Sevilla ME, Nava LE, Malacara JM, et al. Adherence to treatment and social support in patients with non-insulin dependent diabetes mellitus. J Diabetes Complications. 1995;9:81-86.

26. Fleury J. An exploration of the role of social networks in cardiovascular risk reduction. Heart Lung. 1993;22:134-144.

27. Frazier PA, Davis-Ali SH, Dahl KE. Stressors, social support and adjustment in kidney transplant patients and their spouses. Soc Work Health Care. 1995;21:93-108.

28. Gulanick M, Bliley A, Perino B, Keough V. Recovery patterns and lifestyle changes after coronary angioplasty: the patient's perspective. Heart Lung. 1998;27:253-262.

29. Ingram M, Torres E, Redondo F, Bradford G, O'Toole ML. The impact of promotoras on social support and glycemic control among members of a farmworker community on the US-Mexico border. Diabetes Educ. 2007;33:172S-178S.

30. Keeling DI, Price PE, Jones E, Harding KG. Social support: some pragmatic implications for health care professionals. JAdv Nurs. 1996;23: 76-81.

31. Stewart M, Ellerton M, Hart G, et al. Insights from a nursing research program on social support. Can J Nurs Res. 1997;29:93-110.

32. Stewart MJ. Chronic Conditions and Caregiving in Canada: Social Support. Toronto: University of Toronto Press; 2000.

33. Gleeson-Kreig J. Social support and physical activity in type 2 diabetes: a social-ecologic approach. Diabetes Educ. 2008;34:1037-1044.

34. Rosland AM, Kieffer E, Israel B, et al. When is social support important? The association of family support and professional support with specific diabetes self-management behaviors. J Gen Intern Med. 2008;23: 1992-1999.

35. Tang TS, Brown MB, Funnell MM, Anderson RM. Social support, quality of life, and self-care behaviors among African Americans with type 2 diabetes. Diabetes Educ. 2008;34:266-276.

36. Rosenfield S. Factors contributing to the subjective quality of life of the chronic mentally ill. J Health Soc Behav. 1992;33:299-315.

37. Heisler M, Bouknight RR, Hayward RA, Smith DM, Kerr EA. The relative importance of physician communication, participatory decision making, and patient understanding in diabetes self-management. J Gen Intern Med. 2002;17:243-252.

38. Gensichen J, Von Korff M, Rutter CM, et al. Physician support for diabetes patients and clinical outcomes. BMC Public Health. 2009;9: 367-730.
39. Oftedal B, Karlsen B, Bru E. Perceived support from healthcare practitioners among adults with type 2 diabetes. $J A d v$ Nurs. 2010;66: $1500-1509$.

40. Thorne S, Balneaves L, Reimer J. Practical support for women with breast cancer. Can Oncol Nurs J. 1999;9:74-77.

41. Chlebowy DO, Hood S, LaJoie AS. Facilitators and barriers to selfmanagement of type 2 diabetes among urban African American adults: focus group findings. Diabetes Educ. 2010;36:897-905.

42. Martire LM. The 'relative' efficacy of involving family in psychosocial interventions for chronic illness: are there added benefits to patients and family members? Fam Syst Health. 2005;23:312-328.

43. White P, Smith SM, O'Dowd T. The role of the family in adult chronic illness: a review of the literature on type 2 diabetes. Ir J Psychol. 2005;26:9-15.

44. Gallant M. Help or hindrance? How family and friends influence chronic illness self-management among older adults (report). Res Aging. 2007;29:375-377.

45. Carter-Edwards L, Skelly AH, Cagle CS, Appel SJ. "They care but don't understand": family support of African American women with type 2 diabetes. Diabetes Educ. 2004;30:493-501.

46. Franks MM, Stephens MA, Rook KS, Franklin BA, Keteyian SJ, Artinian NT. Spouses' provision of health-related support and control to patients participating in cardiac rehabilitation. J Fam Psychol. 2006;20: 311-318.

47. Beanlands H, Horsburgh ME, Fox S, et al. Caregiving by family and friends of adults receiving dialysis. Nephrol Nurs J. 2005;32: 621-631.

48. Samuel-Hodge CD, Headen SW, Skelly AH, et al. Influences on day-to-day self-management of type 2 diabetes among AfricanAmerican women: spirituality, the multi-caregiver role, and other social context factors. Diabetes Care. 2000;23:928-933.

49. Devlin H, Roberts M, Okaya A, Xiong YM. Our lives were healthier before: focus groups with African American, American Indian, Hispanic/Latino, and Hmong people with diabetes. Health Promot Pract. 2006;7:47-55.

50. Egede LE, Bonadonna RJ. Diabetes self-management in African Americans: an exploration of the role of fatalism. Diabetes Educ. 2003;29:105-115

51. Heuer L, Lausch C. Living with diabetes: perceptions of Hispanic migrant farm workers. J Community Health Nurs. 2006;23:49-64.

52. Chesla CA, Skaff MM, Bartz RJ, Mullan JT, Fischer L. Differences in personal models among Latinos and European Americans. Diabetes Care. 2000;23:1780-1785.

53. Lai WA, Lew-Ting CY, Chie WC. How diabetic patients think about and manage their illness in Taiwan. Diabet Med. 2005;22:286-292.

54. Meetoo D, Meetoo L. Explanatory models of diabetes among Asian and Caucasian participants. Br J Nurs. 2005;14:154-159.

55. Barnes L, Moss-Morris R, Kaufusi M. Illness beliefs and adherence in diabetes mellitus: a comparison between Tongan and European patients. N Z Med J. 2004;117:U743.

56. Hjelm K, Nambozi G. Beliefs about health and illness: a comparison between Ugandan men and women living with diabetes mellitus. Int Nurs Rev. 2008;55:434-441.

57. Hjelm K, Atwine F. Health-care seeking behaviour among persons with diabetes in Uganda: an interview study. BMC Int Health Hum Rights. 2011;11:11.

58. Hasan SS, Ahmed SI, Bukhari NI, Loon WC. Use of complementary and alternative medicine among patients with chronic diseases at outpatient clinics. Complement Ther Clin Pract. 2009;15:152-157.

59. Uganda Singh V, Raidoo DM, Harries CS. The prevalence, patterns of usage and people's attitude towards complementary alternative medicine (CAM) among the Indian community in Chatsworth, South Africa. BMC Complement Altern Med. 2004;4:1-7.

60. Connell CM, Fisher EB, Houston CA. Relationships among social support, diabetes outcomes, and morale for older men and women. J Aging Health. 1992;4:77-100. 
61. Spitze G, Ward R. Gender, marriage, and expectations for personal care. Res Aging. 2000;22:451-469.

62. Murphy DJ, Williamson PS, Nease DE Jr. Supportive family members of diabetic adults. Fam Pract Res J. 1994;14:323-331.

63. Donaldson L. Expert patients usher in a new era of opportunity for the NHS. BMJ. 2003;326:1279-1280.

64. Simmons D, Voyle JA, Rush E, Dear M. The New Zealand experience in peer support interventions among people with diabetes. Fam Pract. 2010;27:i53-i61.

65. Heisler M, Vijan S, Makki F, Piette JD. Diabetes control with reciprocal peer support versus nurse care management. A randomized trial. Ann Intern Med. 2010;153:507-515.

66. Tuerk PW, Mueller M, Egede LE. Estimating physician effect on glycemic control in the treatment of diabetes. Diabetes Care. 2008;31: 869-873.

67. Solomon P. Peer support/peer provided services: underlying processes, benefits, and critical ingredients. Psychiatr Rehabil J. 2004;27: 392-401.

68. Vijan S, Hayward RA, Ronis DL, Hofer TP. Brief report: the burden of diabetes therapy: implications for the design of effective patientcentered treatment regimens. J Gen Intern Med. 2005;20:479-482.

69. Fisher EB, Boothroyd RI, Coufal MM, et al. Peer support for selfmanagement of diabetes improved outcomes in international settings. Health Aff. 2012;31:130-139.

70. Selden C, Zorn ME, Parker R, Ratzan SC. Health literacy. 2000. Available from: http://www.nlm.nih.gov/archive//20061214/pubs/cbm/ hliteracy.html. Accessed October 17, 2012.

71. Williams MV, Baker DW, Parker RM, Nurss JR. Relationship of functional health literacy to patients' knowledge of their chronic disease A study of patients with hypertension and diabetes. Arch Intern Med. 1998;158:166-172.

72. Gazmararian JA, Kripalani S, Miller MJ, Echt KV, Ren J, Rask K. Factors associated with medication refill adherence in cardiovascularrelated diseases: a focus on health literacy. J Gen Intern Med. 2006;21: 1215-1221.

73. Tang YH, Pang SM, Chan MF, Yeung GS, Yeung VT. Health literacy, complication awareness, and diabetic control in patients with type 2 diabetes mellitus. J Adv Nurs. 2008;62:74-83.

74. Bass PF 3rd, Wilson JF, Griffith CH, Barnett DR. Residents' ability to identify patients with poor literacy skills. Acad Med. 2002;77: 1039-1041.

75. Cavanaugh K, Huizinga MM, Wallston KA, et al. Association of numeracy and diabetes control. Ann Intern Med. 2008;148:737-746.
76. Morris NS, MacLean CD, Littenberg B. Literacy and health outcomes: a cross-sectional study in 1002 adults with diabetes. BMC Fam Pract. 2006;7:49.

77. Weiss BD, Palmer R. Relationship between health care costs and very low literacy skills in a medically needy and indigent Medicaid population. J Am Board Fam Pract. 2004;17:44-47.

78. Persell SD, Osborn CY, Richard R, Skripkauskas S, Wolf MS. Limited health literacy is a barrier to medication reconciliation in ambulatory care. J Gen Intern Med. 2007;22:1523-1526.

79. Bains SS, Egede LE. Associations between health literacy, diabetes knowledge, self-care behaviors, and glycemic control in a low income population with type 2 diabetes. Diabetes Technol Ther. 2011;13: 335-340.

80. Osborn CY, Bains SS, Egede LE. Health literacy, diabetes self-care, and glycemic control in adults with type 2 diabetes. Diabetes Technol Ther. 2010;12:913-919.

81. Angelmar R, Berman PC. Patient empowerment and efficient health outcomes. Report 3 from Sustainable Healthcare Financing: new approaches for new outcomes conference, Helsinki, Feb 2007. Available from: http://www.drmed.org/javne_datoteke/novice/datoteke/10483Report_3.pdf. Accessed July 17, 2012.

82. International Diabetes Federation. International Standards for Diabetes Education. 3rd edition. Brussels: IDF; 2009.

83. Schillinger D, Piette J, Grumbach K, et al. Closing the loop: physician communication with diabetic patients who have low health literacy. Arch Intern Med. 2003;163:83-90.

84. Paasche-Orlow MK, Wolf MS. Evidence does not support clinical screening of literacy. J Gen Intern Med. 2008;23:100-102.

85. Chew LD, Griffin JM, Partin MR, et al. Validation of screening questions for limited health literacy in a large VA outpatient population. J Gen Intern Med. 2008;23:561-566.

86. Jeppesen KM, Coyle JD, Miser WF. Screening questions to predict limited health literacy: a cross-sectional study of patients with diabetes mellitus. Ann Fam Med. 2009;7:24-31.

87. Safeer RS, Keenan J. Health literacy: the gap between physicians and patients. Am Fam Physician. 2005;72:463-468.

88. Paasche-Orlow MK, Riekert KA, Bilderback A, et al. Tailored education may reduce health literacy disparities in asthma self-management Am J Respir Crit Care Med. 2005;172:980-986.

89. Schillinger D, Grumbach K, Piette J, et al. Association of health literacy with diabetes outcomes. JAMA. 2002;288:475-482.

\section{Publish your work in this journal}

Diabetes, Metabolic Syndrome and Obesity: Targets and Therapy is an international, peer-reviewed open-access journal committed to the rapid publication of the latest laboratory and clinical findings in the fields of diabetes, metabolic syndrome and obesity research. Original research, review, case reports, hypothesis formation, expert opinion and commentaries are all considered for publication. The manuscript management system is completely online and includes a very quick and fair peer-review system, which is all easy to use. Visit http://www.dovepress.com/testimonials.php to read real quotes from published authors. 